\title{
Article
}

\section{Tensile Behavior of Geometrically Irregular Bagasse Fiber}

\author{
Md Shahnewaz Bhuiyan *, Muhommad Azizur Rahman * ${ }^{\mathbb{D}}$, Md Shahriar Farabi and Md Mahedi Hasan \\ Department of Mechanical and Production Engineering, Ahsanullah University of Science and Technology, \\ Dhaka 1208, Bangladesh; 160108016@aust.edu (M.S.F.); 160108028@aust.edu (M.M.H.) \\ * Correspondence: newaz.mpe@aust.edu (M.S.B.); aziz.mpe@aust.edu (M.A.R.); \\ Tel.: +88-02-8878266 (ext. 266) (M.S.B.); +88-02-8878266 (ext. 238) (M.A.R.)
}

check for updates

Citation: Bhuiyan, M.S.; Rahman, M.A.; Farabi, M.S.; Hasan, M.M. Tensile Behavior of Geometrically Irregular Bagasse Fiber. Appl. Mech. 2021, 2, 274-288. https://doi.org/ 10.3390/applmech2020017

Received: 6 April 2021

Accepted: 13 May 2021

Published: 16 May 2021

Publisher's Note: MDPI stays neutral with regard to jurisdictional claims in published maps and institutional affiliations.

\begin{abstract}
In the present work, an investigation on the surface topography and geometry variation of bagasse fibers was correlated with their mechanical properties via image analysis. The fibers were tested under a universal tensile testing machine and the diameter of the fibers was calculated using images obtained in a digital microscope. Furthermore, surface characterization and quantification were also performed using images obtained via SEM. The results showed that the surface roughness of alkali-treated bagasse fiber increased compared to that of the untreated one. Moreover, it was observed that the diameter variation of bagasse fiber along its length and among different fibers is not only variable but also unpredictable. The tensile test results revealed that bagasse fibers showed lower stress at a rupture with considerable scatter. It can be inferred that the synergistic effect of thick bagasse fiber, bagasse fiber diameter variations along its length and among fibers, and the fiber fracture mechanism establishes a local condition for fracture and resulted in such variations in tensile properties. Finally, the results clearly showed that the two-parameter Weibull fit the experimental data fairly well $\left(R^{2}=0.97\right)$. The Weibull modulus $(m)$ was found to be 1.7 , indicating that the strength distribution is high.
\end{abstract}

Keywords: bagasse fiber; Weibull distribution; mechanical properties; scanning electron microscopy

\section{Introduction}

Research and development of eco-friendly, green, and sustainable composite materials using agro-based or lignocellulose materials have been attracting increasing research attention in recent years. The attractive characteristics of natural fibers whereby they are economic, lightweight, biodegradable, zero carbon footprint, environmentally friendly and nonabrasive, and exhibit interesting physical and mechanical properties such as low density, high specific properties, high aspect ratio, relatively high processing flexibility, and good strength $[1,2]$ make them attractive for use in composite materials. In recent decades, much research has been directed towards the use of various lignocellulose-based fibers as reinforcement for plastics. Various types of natural fibers are used as reinforcement of composite such as flax fibers [3], bamboo fibers [4], jute fiber [5], kenaf fiber [6], sisal fiber [7], coir [8], abaca [9], and wheat straw [10].

In Bangladesh, on average, about 0.13 million ha of land is used to cultivate sugarcane and the annual production is about 7.5 million tons [11]. During the scorching summer, people - especially day laborers, rickshaw pullers, and other low-income groups-consume sugarcane juice sold by street vendors as they are inexpensive, convenient, and attractive. Street vendors roam around the city with hand or motor-driven crushing machine and sugarcane on their vans (Figure 1). The "bagasse" (the fiber residue that is left after the juice extraction from sugarcane) is dumped into the environment by the street vendors. Bangladesh produces about 800,000 tons of bagasse per year and is considered as one of the most important agricultural residues in the country [11]. Therefore, proper consumption of this bagasse is necessary by implementing proper valorization technologies and must be handled in an environmentally friendly and economically advantageous way. 


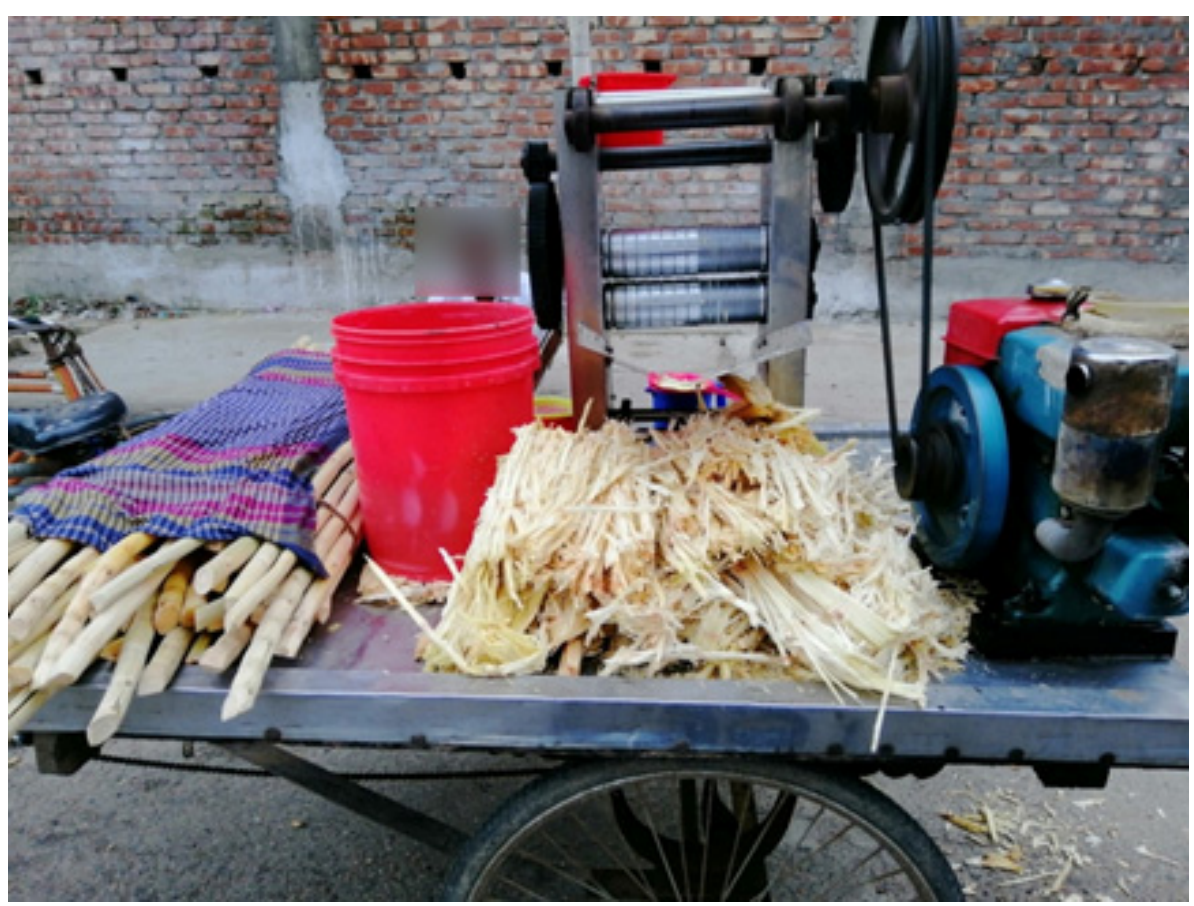

Figure 1. Street vendors with motor-driven crushing machine and sugarcane on their vans.

Inspection of the published studies, however, revealed that the three main components of bagasse are cellulose, hemicellulose, and lignin, which have reasonable mechanical properties with ultimate tensile strength (UTS) ranging from 170-290 MPa, and modulus of elasticity in the range of 15-19 GPa [12,13]. Hence, bagasse is considered a promising fiber for reinforcing filler for composites, either in thermoplastics or thermoset matrices.

Like other natural fibers, the main bottlenecks of bagasse fiber utilized in reinforcement to composites are high moisture absorption and poor interfacial adhesion with the matrix [14]. To address these limitations, significant research has been carried out in the last decade and can be broadly classified into two groups, namely (i) matrices for composites and (ii) modification of surface properties of bagasse fibers. The shape, surface appearance, durability, and environmental tolerance of composites are dominated by the matrix while the macroscopic stiffness and strength of composites are dominated by reinforced fibers by carrying most of the structural load. Hence, the research on the matrices for composites group was mainly focused on the incorporation of bagasse fibers in thermoplastics such as bagasse-fiber reinforced with polypropylene composite [14,15], bagasse-fiber reinforced with polyester composites [12,16,17], bagasse-fiber reinforced with poly (ethylene vinyl acetate) composites [18], bagasse reinforced polyethylene composites [19], bagasse reinforced with polypro and thermoset matrix bagasse epoxy bio-degradable composite [19]. On the other hand, the modification of surface properties of bagasse fibers research is carried out to improve the adhesion characteristics of bagasse fibers either in thermoplastics or thermoset matrices. A favorable strength and stiffness could be achieved with a strong interface using physical methods (such as mechanical activation treatment [20]), chemical methods such as mercerization or alkaline treatment [13,14,21-23], acetylation [13], methylation, benzoylation, permanganate treatment, acrylation, esterification $[19,24,25]$. However, mercerization is found to be the most widely used chemical treatment for bagasse [24].

In comparison with synthetic fibers such as carbon and glass fiber, bagasse fiber exhibits much higher variation not only in terms of morphology, surface characteristics, mechanical, physical, and chemical properties, but also they present a geometry variation. The diameter of bagasse fiber varies not only among fibers but also along the fiber length, resulting in significant scattering in the fiber mechanical properties. Consequently, this may result in considerable variation in the fiber strengths and hence, cannot be characterized 
completely using deterministic models. The scattering characteristics of bagasse fiber need to be assessed statistically. Usually, the Weibull distribution that is commonly used to evaluate the strength distribution of brittle materials, has now been shown to give a reasonable fit to fiber strength at a single gauge length for natural fibers [26,27].

Aiming to use bagasse fibers as reinforcing agents for either thermoplastics or thermoset matrices, this work focuses on the characterization of alkali-treated bagasse fibers. The fiber diameter was estimated from a digital microscope image, whereas the fiber surface characterization and quantification were performed by obtaining scanning electron microscopy images. Finally, the two-parameter Weibull distribution was used to model the fracture probability of the above-mentioned bagasse fibers

\section{The Weibull Distribution}

The Weibull distribution [28] relies on the 'weakest link hypothesis' which means that the most detrimental flaw in the material will control the strength. In the case of bagasse fiber, the weakest point relies on where there is a defect or where the fiber diameter is at a minimum, or a combination of both. The fibers fracture when this weakest point reaches its breaking limit. Therefore, it is reasonable to assume that the fiber failure load is the characteristics of the fiber and the measured strength of bagasse fibers exhibits a distribution. However, the variations in fiber strength are commonly subjected to further detailed analysis using a two-parameter Weibull distribution, which takes the form as per the below Equation (1) [29]:

$$
F\left(\sigma_{f} ; \sigma_{0}, \alpha\right)=1-\exp \left[\left(-\frac{\sigma_{f}}{\sigma_{0}}\right)^{\alpha}\right] \sigma_{0}>0, \alpha>0
$$

Here, $F\left(\sigma_{f} ; \sigma_{0}, \alpha\right)$ represents the failure probability; $\sigma_{0}$ represents the scale parameter, where failure probability is $63.2 \%$; $\sigma_{f}$ represents the variable (fiber fracture load in the present study); $\alpha$ represents the shape parameter (alternatively referred to as Weibull modulus), which is a measure of both data scattering and the scale parameter $\sigma_{0}$.

The shape parameter, $\alpha$, is predicted using one of three methods: (i) linear regression, (ii) maximum likelihood, and (iii) moments. Among these, linear regression is the most widely used method, mainly because of its simplicity and relative ease of use [28].

Taking the natural logarithm of both sides of Equation (1) twice yields the following:

$$
\ln \left[\ln \left(\frac{1}{1-F\left(\sigma_{f} ; \sigma_{o}, \alpha\right.}\right)\right]=\alpha \ln \left(\sigma_{f}\right)-\alpha \ln \left(\sigma_{o}\right)=\alpha x+c
$$

To evaluate the value of $\alpha$ and $\sigma_{o}$, the experimental values of $\sigma_{f}$ were arranged in ascending order. Then, a good estimate of $F\left(\sigma_{f} ; \sigma_{0}, \alpha\right)$ is the median rank of $\sigma_{f}$, which is calculated using the following expression [4]:

$$
F\left(\sigma_{f} ; \sigma_{0}, \alpha\right)=\frac{i-0.3}{n+0.4}
$$

Here, $i$ represents the rank of the respective data point in ascending order, and $n$ represents the sample number (20 in the present study)

After plotting $\ln \left[\ln \left(\frac{1}{1-F\left(\sigma_{f} ; \sigma_{0}, \alpha\right.}\right)\right]$ versus $\ln \left(\sigma_{f}\right)$, a linear regression of the data points is utilized to calculate the Weibull modulus, $\alpha$, and the characteristic tensile strength, $\sigma_{0}$. The slope of the regressed line represents the Weibull modulus, $m$, whereas the characteristic tensile strength, $\sigma_{0}$, is calculated from the intercept $\left(\alpha \ln \left(\sigma_{o}\right)\right)$. In the regression model, the precision adjustment parameter, $R^{2}$, can be used to assess the goodness of fit between the function and experimental data. For all sample sizes, $R^{2}>0.95$ indicates a good fit, $R^{2}<0.90$ indicates a poor fit, and no guidance was provided for $R^{2}$ values between 0.95 and 0.90 [30]. 


\section{Materials and Methods}

\subsection{Material}

The bagasse fibers used in the present study were collected from street vendors. Figure 2a shows the fibrous residue, after the extraction of juice from sugarcane by roll pressing, dumped into the environment. The as-collected fibrous residue (shown in Figure 2a) was washed thoroughly in running water and then dried for $72 \mathrm{~h}$ under the sun. The bagasse was then washed with warm water at $70{ }^{\circ} \mathrm{C}$ for $3 \mathrm{~h}$ and dried under the sun for another $72 \mathrm{~h}$. This was done to remove any remaining sugar residue and undesirable foreign matter in the bagasse. Bagasse fibers were then manually extracted from the dried fibrous residue, as shown in Figure $2 b$. Hereinafter, the dried bagasse fibers were designated as untreated bagasse fibers.
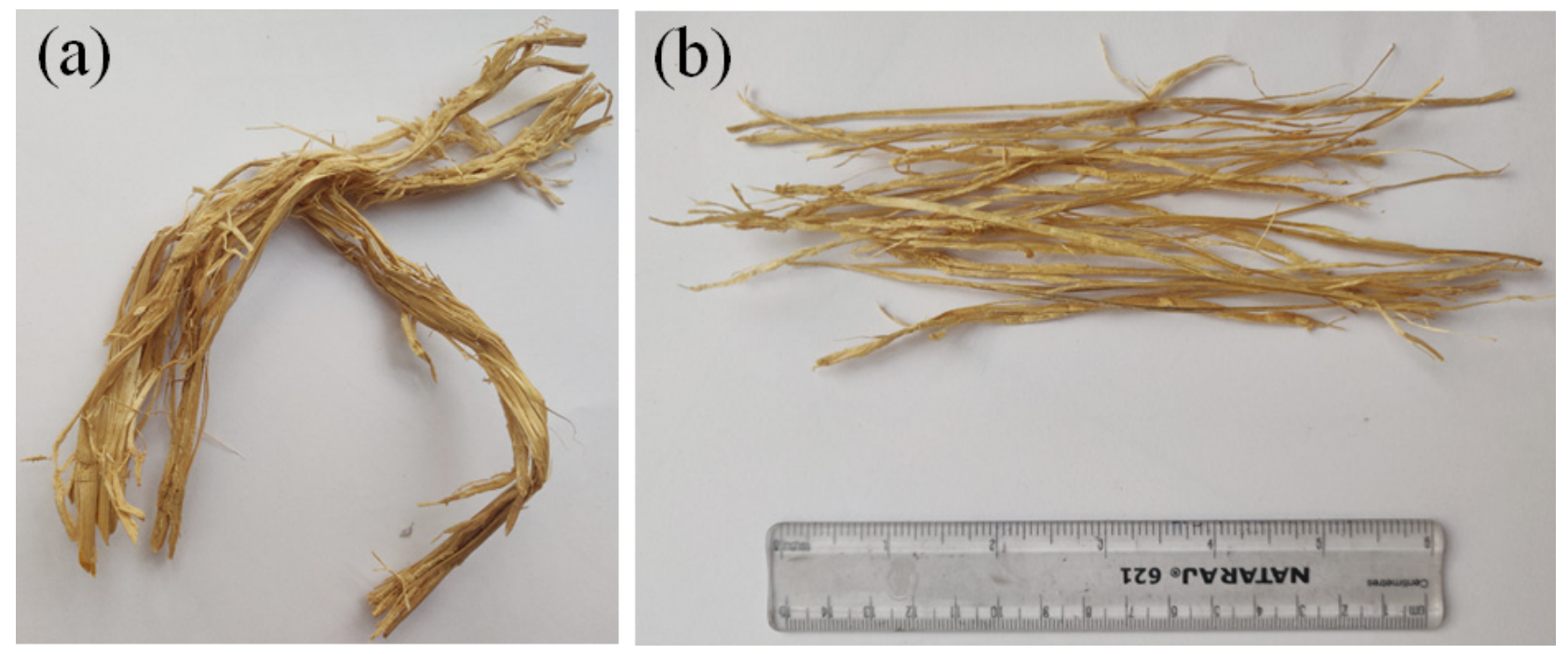

Figure 2. Bagasse fibers: (a) fibrous residue collected from street vendor, (b) manually picked fibers.

\subsection{Chemical Treatment}

Alkaline treatment was used to treat the bagasse fibers, wherein a $1 \% \mathrm{NaOH}$ was used to soak the fibers for $3 \mathrm{~h}$ at ambient temperature. The bagasse fibers were washed thoroughly in water to ensure all excess $\mathrm{NaOH}$ that may stick to the fiber surface is removed and the fibers were dried under the sun for $72 \mathrm{~h}$. Hereinafter, the chemically treated bagasse fibers were designated as treated bagasse fibers. The details of the preparation of the bagasse fibers are shown in Figure 3.

\subsection{Fiber Diameter Measurement}

To measure the diameter variation of bagasse fiber within and along its length, the treated fibers were observed using a Motic AE 2000 microscope. The microscope was equipped with Motic image plus 3.0 software. In total, 20 randomly selected bagasse fibers were observed and images were captured.

After the acquisition, Image J version $1.53 \mathrm{~g}$ was used for processing and analyzing the images. First, the images were converted to 8-bit images. Then, the scale bar at the bottom of the image was used to calibrate the image and the known distance was transformed from pixels into micrometers. The 8-bit images were then converted into binary images using conventional thresholding in ImageJ (Figure 4). The diameter of the bagasse fiber along its length was calculated using the line segments. The measurement was conducted at 20 different locations along each sample length. 


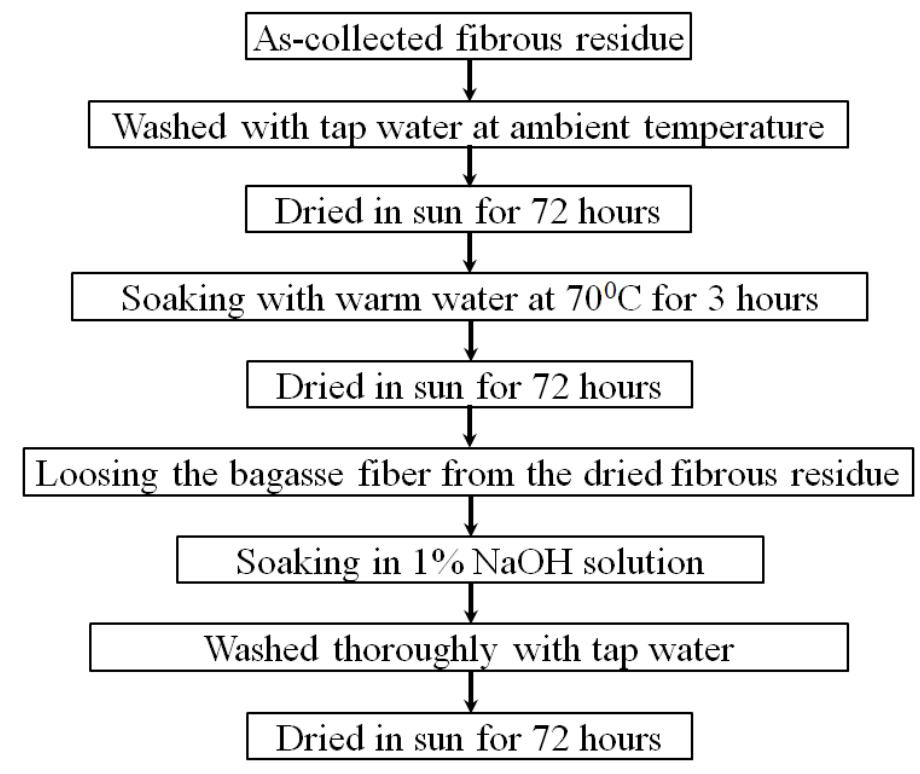

Figure 3. Flow chart highlighting the steps employed in preparation of bagasse fiber.
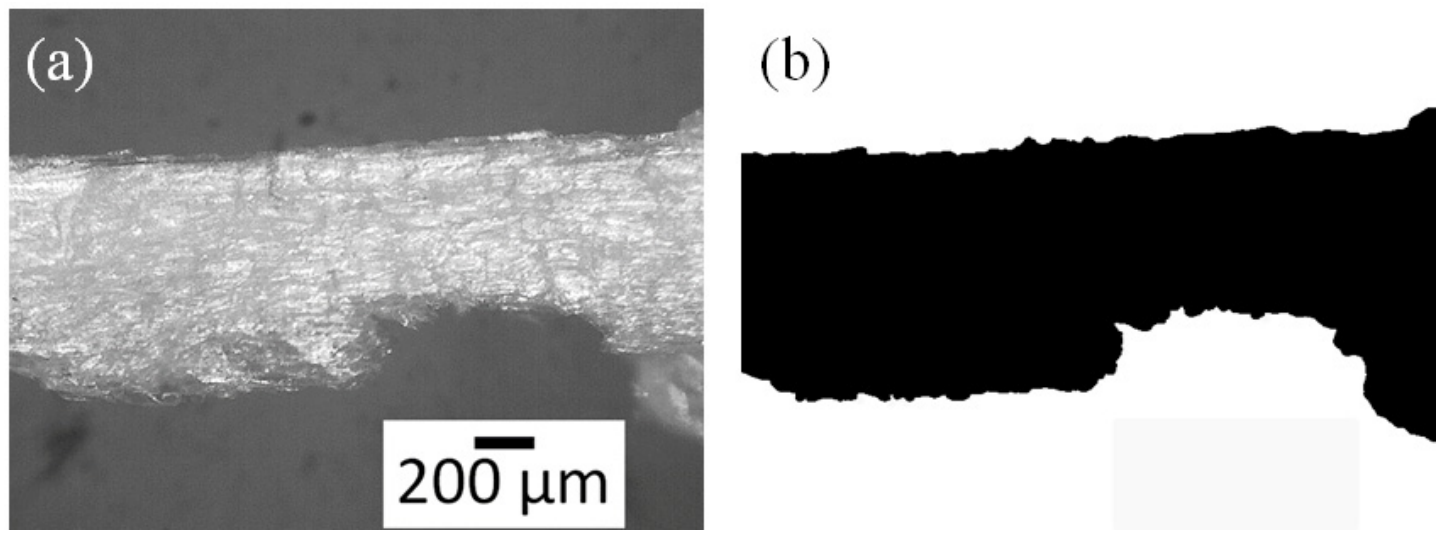

Figure 4. Segmentation of bagasse fiber (a) 8 bit image, (b) binary image from thresholding in ImageJ.

The surface morphology of untreated and treated bagasse fibers was investigated by capturing the images in a scanning electron microscope (TESCAN VEGA 3). These high-resolution SEM images were further processed to understand the surface profiles of untreated and treated bagasse fibers using Image J software [31]

\subsection{Tensile Testing}

The tensile properties of fibers can be obtained either by single fiber tensile testing (SFTT) [32] or by bundle fiber tensile testing (BFTT)) [33]. Though SFTT is a laborious and time-consuming process, this process is the most straightforward, most reliable, and unambiguous means of characterizing fibers or exploring their morphologies. Therefore, the SFTT method was applied in the present study.

All the single fiber tensile tests were carried out using a Titan Universal Tensile Testing machine with a $200 \mathrm{~N}$ load cell and a gauge length of $75 \mathrm{~mm}$ and $10 \mathrm{~mm} / \mathrm{min}$ crosshead speed. In total, 20 single bagasse fibers were tested. The load-displacement curve was recorded during the test. 


\section{Results \\ 4.1. Surface Morphology of Bagasse Fiber}

Figure 5 shows the SEM images of both untreated and treated bagasse fiber. As can be seen, compared to untreated bagasse fiber, the alkali-treated bagasse fiber showed a cleaner surface. The literature review revealed that during alkali treatment, a certain amount of lignin, hemicellulose, and pectin covering the surface, inorganic materials, non-cellulose substances, and waxes are removed, resulting in fibers with a cleaner yet uneven surface [21]. Therefore, it is customary to distinguish the surface morphology of untreated and treated bagasse fiber used in the present study.
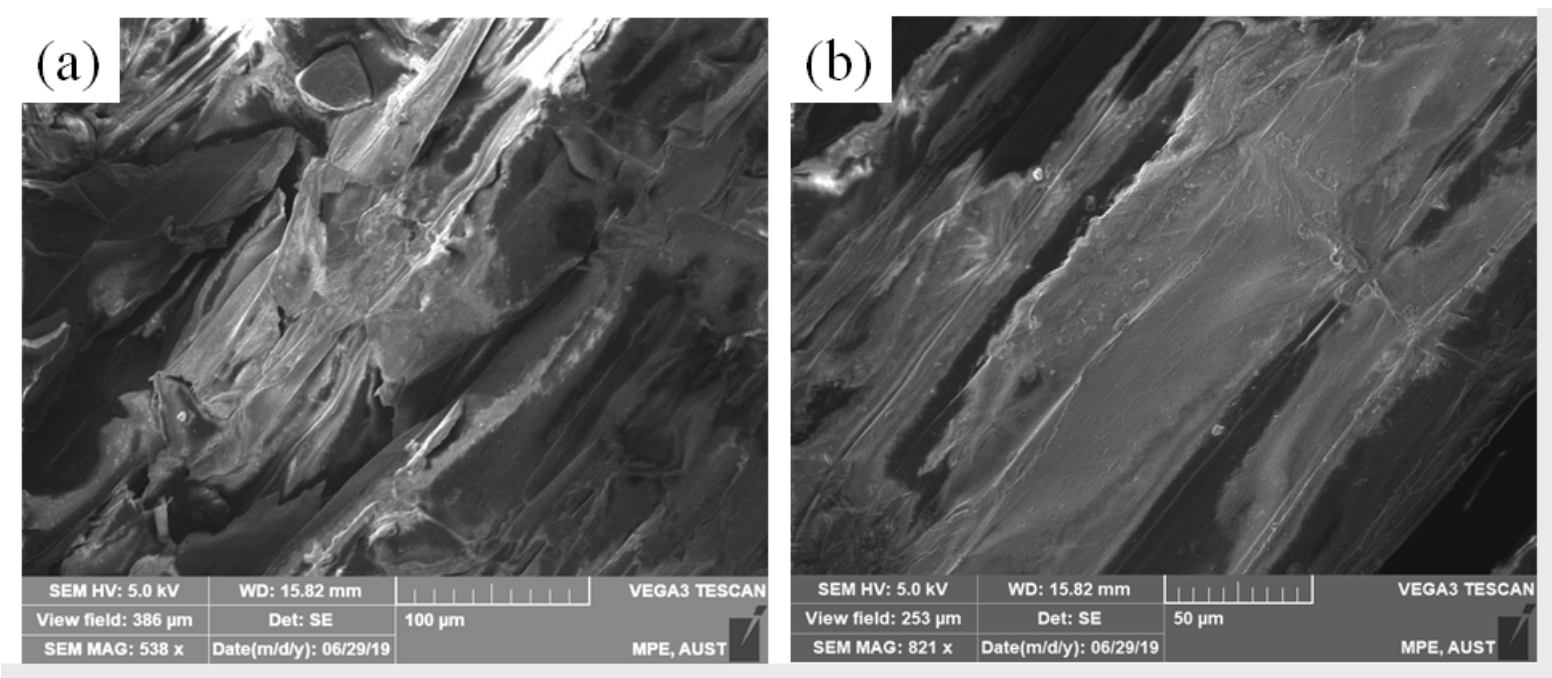

Figure 5. SEM image of single sugarcane bagasse fiber: (a) untreated, (b) treated.

Traditionally, various techniques have been used for measuring surface roughness, ranging from mechanical profilers [34] to more sophisticated optical techniques such as optical profilers [35], laser profilometry [35], atomic force microscopy [35], indicating that no universal technique exits to measure or describe surface morphology. Recently, Scanning Electron Microscopic imaging combined with image analysis software is used for assessing the quantitative surface morphology [36-38]. In the present study, surface characterization and quantification were performed with an ImageJ plugin (version $1.51 \mathrm{k}$ ) for surface assessment, called the SurfCharJ plugin [39]. Various surface roughness parameters such as root mean square deviation $\left(R_{q}\right)$, arithmetic mean deviation $\left(R_{a}\right)$, kurtosis of the assessed profile $\left(R_{k u}\right)$, skewness of the assessed profile $\left(R_{s k}\right)$, lowest valley (given by the minimum measurements) $\left(R_{V}\right)$, highest valley (given by the maximum measurements) $\left(R_{p}\right)$, and the total height of the profile $\left(R_{t}\right)$ can be obtained in accordance with ISO $4287 / 200$ standard. For details about surface roughness parameters and image measurement, the procedure is documented elsewhere [40].

Figure 6 shows typical cross-sectional line profiles obtained by ImageJ. Each of these profiles was generated by selecting one line from the corresponding 2D SEM images and is shown in Figure 6a,c. Compared to untreated bagasse fiber, the grayscale value amplitude of treated bagasse fiber changes. It could also be seen that the grayscale value is high in treated bagasse fibers compared to that of untreated bagasse fibers. Figure 7 shows three-dimensional surface topography images of both untreated (Figure 7a) and treated bagasse fibers (Figure $7 \mathrm{~b}$ ). Though both surfaces are characterized by irregularly distributed peaks, treated bagasse fibers showed more peaks. To quantitatively assess the roughness between untreated and treated bagasse fiber, average roughness parameters $R_{q}, R_{a}, R_{k u}, R_{s k}, R_{V}, R_{p}$, and $R_{t}$ were calculated using the SurfCharJ plugin and are shown in Table 1. From Table 1, it is clear that the average value of root mean square deviation $\left(R_{q}\right)$, and arithmetic mean deviation $\left(R_{a}\right)$ of treated fibers is about 1.5 times and 
1.6 times larger than that of untreated fibers, respectively. The ratios of highest valley to lowest valley $\left(\frac{R_{P}}{R_{V}}\right)$ for both untreated and treated bagasse fibers are about 6.3 and 6.6, respectively. This indicates that the surface of treated bagasse fibers has high peaks, which is in agreement with Figure 7. However, the average roughness $\left(R_{a}\right)$ and the root mean squared (RMS) roughness $\left(R_{q}\right)$ are most widely used to characterize the surface quality, both $R_{a}$ and $R_{q}$ parameters did not offer any insight into the horizontal dimensions of the surface. Therefore, some authors recommended the use of additional parameters such as skewness $\left(R_{s k}\right)$ and kurtosis $\left(R_{k u}\right)[41,42]$. Our results clearly show that both untreated and treated bagasse fibers have positively skewed $\left(R_{s k}\right.$ is positive indicating that profile with high peaks) and leptokurtic $\left(R_{k u}>3\right.$ indicating that the distribution has a relatively high number of high peaks and low valley) distributions.
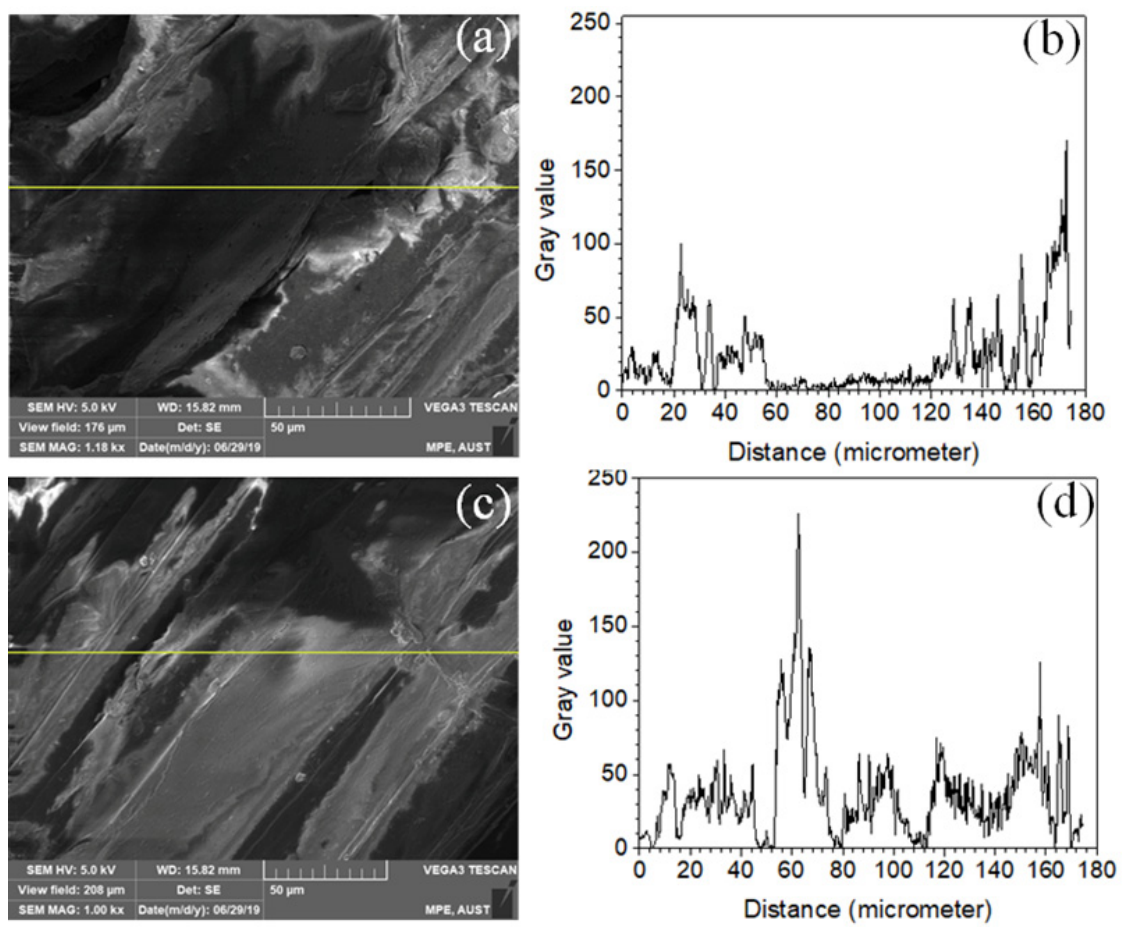

Figure 6. Typical two-dimensional images and cross-sectional gray value profile showing: (a,b) untreated fibers, $(\mathbf{c}, \mathbf{d})$ treated fibers.
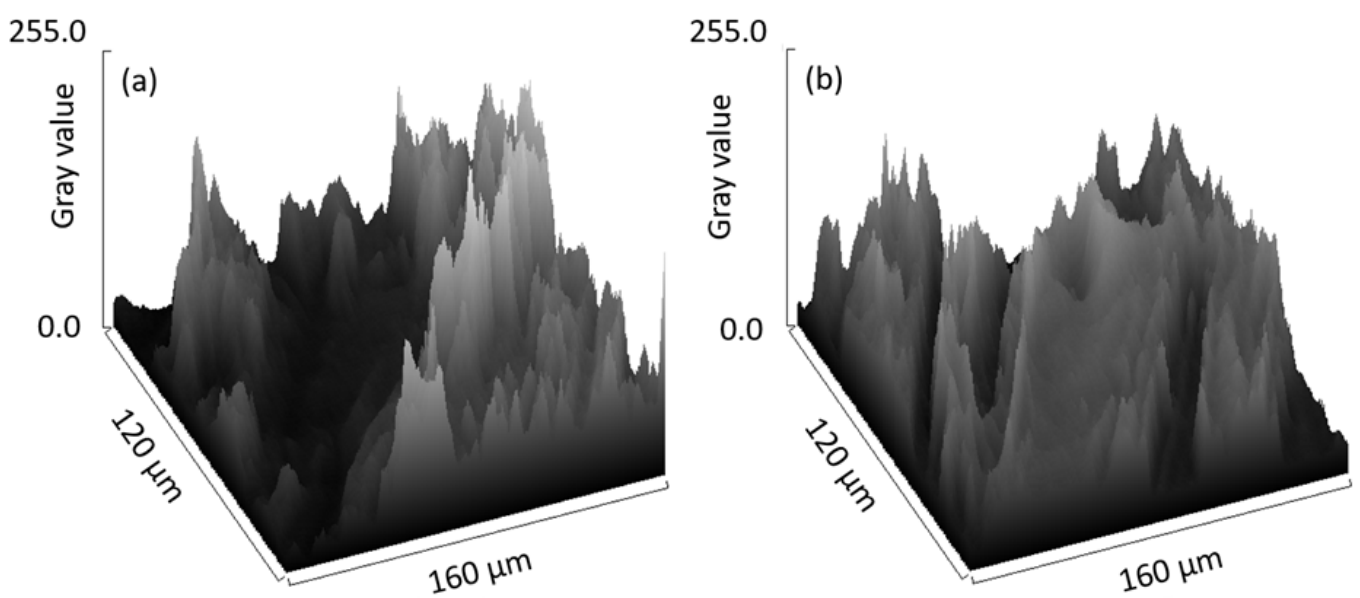

Figure 7. Three-dimensional surface topography images of (a) untreated bagasse fiber, (b) treated bagasse fiber. 
Table 1. Average roughness parameters of untreated and treated bagasse fibers.

\begin{tabular}{cccccccc}
\hline & \multicolumn{8}{c}{ Roughness Parameter } \\
\hline & $\begin{array}{c}\boldsymbol{R}_{\boldsymbol{q}} \\
\text { (Pixels) }\end{array}$ & $\begin{array}{c}\boldsymbol{R}_{\boldsymbol{a}} \\
\text { (Pixels) }\end{array}$ & $\begin{array}{c}\boldsymbol{R}_{\boldsymbol{k} u} \\
\text { (Pixels) }\end{array}$ & $\begin{array}{c}\boldsymbol{R}_{\boldsymbol{s k}} \\
\text { (Pixels) }\end{array}$ & $\begin{array}{c}\boldsymbol{R}_{V} \\
\text { (Pixels) }\end{array}$ & $\begin{array}{c}\boldsymbol{R}_{\boldsymbol{p}} \\
\text { (Pixels) }\end{array}$ & $\begin{array}{c}\boldsymbol{R}_{\boldsymbol{t}} \\
\text { (Pixels) }\end{array}$ \\
\hline Untreated & 21.8 & 15.7 & 5.7438 & 5.7 & 27.5 & 172.9 & 230.8 \\
Treated & 34.3 & 22.9 & 5.6385 & 7.7 & 30.0 & 197.6 & 227.6 \\
\hline
\end{tabular}

Based on the aforementioned discussion, it is clear that the alkali treatment changes the surface morphology of bagasse fibers, making the surface of the fiber cleaner yet rougher.

\subsection{Diameter Variation along the Fiber and between Fibers}

Figure 8 shows the diameter distribution along the fiber length of randomly selected bagasse fibers. The bagasse fiber studied showed a considerable amount of diameter variation along its length. Like other natural fibers, bagasse fiber has also shown nonuniform dimensions. However, here it is shown for the first time that marked differences in diameter distribution may occur along the fiber length.
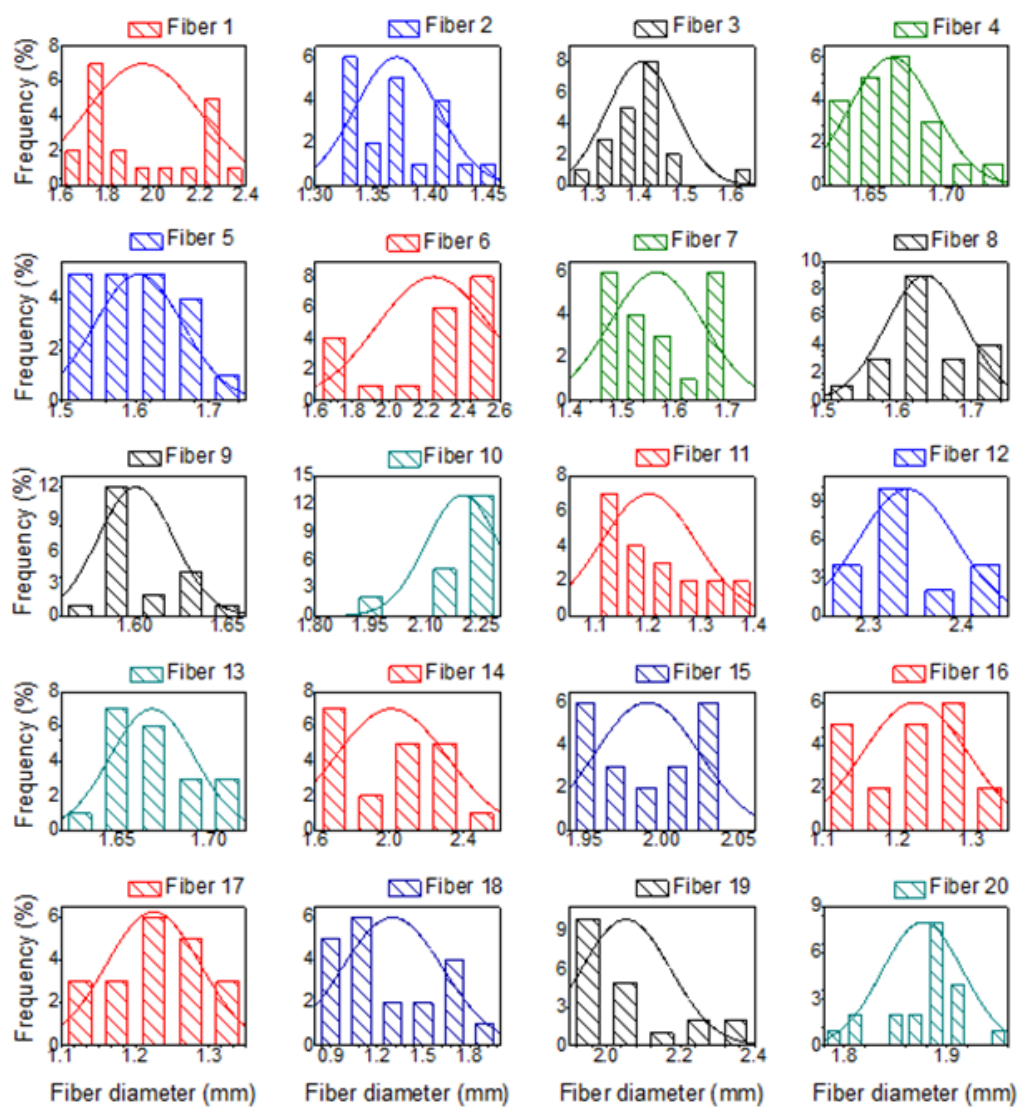

Figure 8. Variation of bagasse fiber (alkali treated) diameter along its length.

The average diameter of each bagasse fiber was actually the average value obtained by 20 different measurements performed along each sample length. Figure 9 shows the average diameter distribution of 20 arbitrarily selected bagasse fibers. The histogram revealed a relatively large scatter in the diameter $(1.1$ to $2.3 \mathrm{~mm})$ and was perhaps due to the fiber extraction method used in the present study. A similar large dispersion in diameter has been found in piassava [43] fibers. Moreover, investigations on a greater number of fibers could possibly extend the range of histograms by finding even thinner and thicker bagasse fibers. However, this study revealed that the diameter of a bagasse fiber along its length and among different fibers showed considerable scatter. 


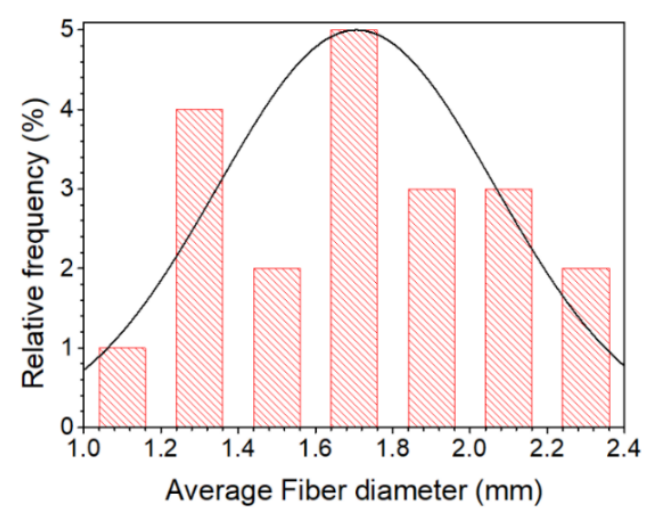

Figure 9. Diameter variation among different bagasse fibers (alkali treated).

\subsection{Tensile Properties}

Figure 10a showed typical load versus elongation curves for all 20 randomly selected bagasse fibers. Despite variability in the breaking load, the load-elongation curves showed a characteristic trend in all samples. Note that each bagasse fiber showed a different deformation rate until breaking point (Figure $\left.10 b^{\prime}, b^{\prime \prime}, b^{\prime \prime \prime}\right)$. Careful observation revealed that bagasse fibers initially showed linear elastic behavior followed by sudden failure with no apparent plastic extension. Other lignocellulosic fibers such as the giant bamboo fibers also showed similar stretching behavior [44]. Based on the maximum load, as shown in Figure 10a, the tensile strength of each fiber was calculated. It is found that the mean tensile strength of the studied bagasse fiber is about 7.3 MPa. Note that the diameter of bagasse fibers used in the present study ranged between 1.1 to $2.3 \mathrm{~mm}$, with a gauge length of $75 \mathrm{~mm}$. Several researchers reported that both fiber diameter and fiber length are negatively correlated with fiber strength $[45,46]$. The present work also shows a similar decreasing trend in fiber strength with increasing fiber gauge length and fiber diameter, as shown in Figure 11. Therefore, the observed low fiber strength in the present study might be due to the use of bagasse fibers with a relatively larger diameter and longer gauge length.
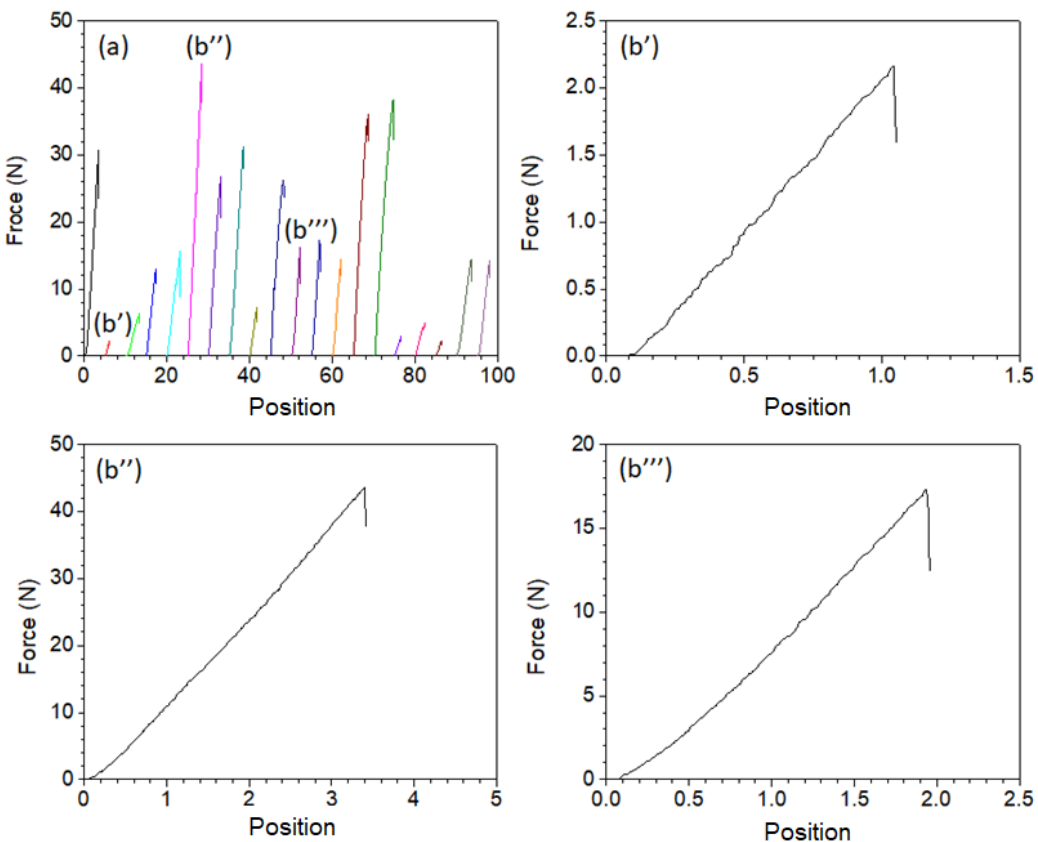

Figure 10. Typical tensile load vs. displacement curve of alkali-treated bagasse fibers showing: (a) all the tested fibers, $\left(\mathbf{b}^{\prime}, \mathbf{b}^{\prime \prime}, \mathbf{b}^{\prime \prime \prime}\right)$. 

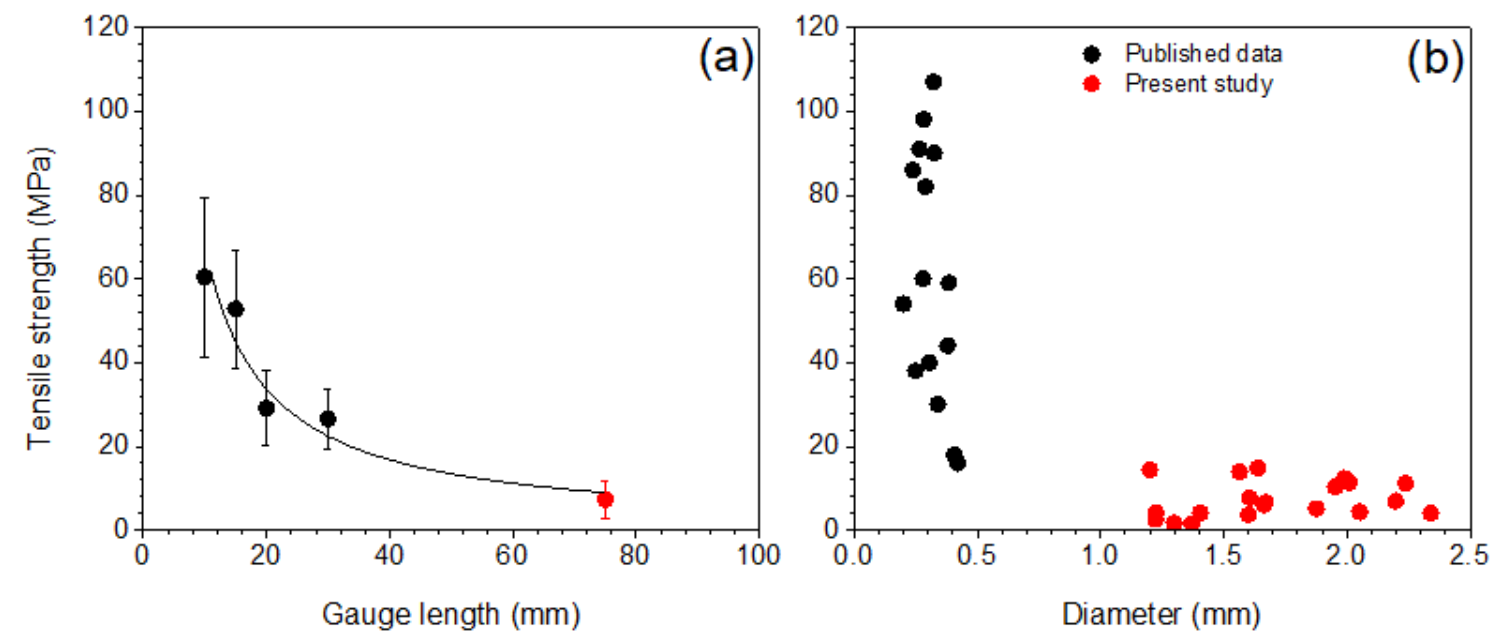

Figure 11. Dependence of bagasse fiber strength on: (a) fiber gauge length, and (b) fiber diameter. Red circles represent the data obtained in the present study, whereas the black circles represent the data adopted from Studies on lignocellulosic fibers of Brazil: Part III-morphology and properties of Brazilian curaua fibers by Tomczak, F.; Satyanarayan, G.; Sydenstricker, T.H.D. Compos. Part A Appl. Sci. Manuf. 2007, 38, 2227-2236.

\subsection{Weibull Analysis of Bagasse Fiber Tensile Strength}

The load versus elongation curve (shown in Figure 10) revealed that the bagasse fiber tensile strength varied, which is characteristic of natural fibers [46,47]. Such variability can be statistically analyzed by the two-parameter Weibull method. Figure 12 shows the Weibull plots based on least-squares fit. The Weibull modulus, $\alpha$, was obtained from the slope of the linear regression model. The scale parameter, $\sigma_{0}$, was calculated using the point at which a unimodal straight line specified by the regression model intersects the $Y$-axis in the expression

$$
\sigma_{0}=\exp ^{-\left(\frac{c}{\alpha}\right)}
$$

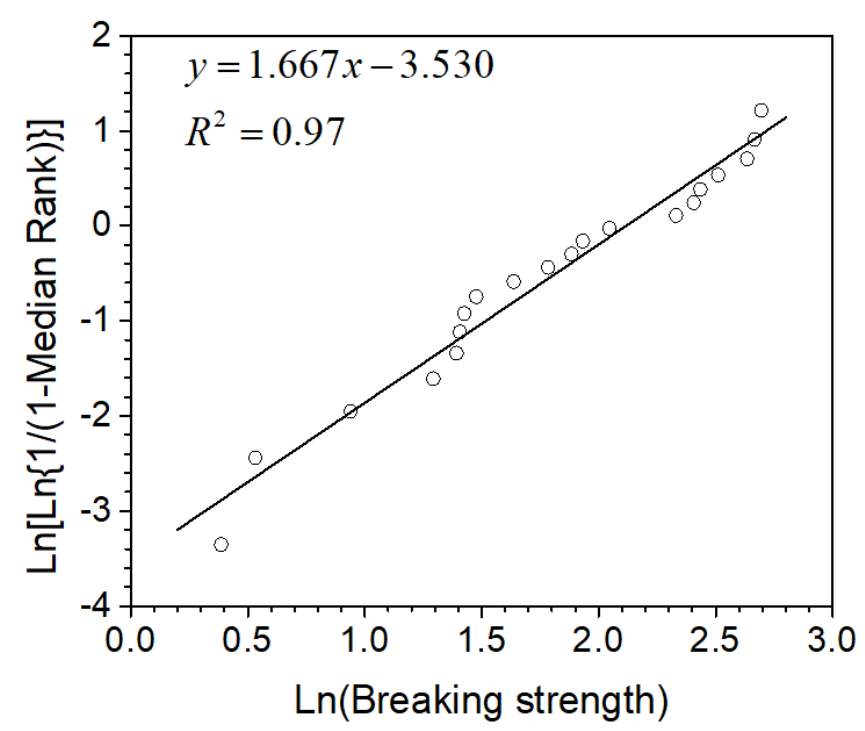

Figure 12. Two parameter Weibull plots of breaking strength taken from 20 bagasse fibers.

Table 2 shows the Weibull modulus, the scale parameter, and the correlation coefficient $\left(R^{2}\right)$ of the Weibull model for bagasse fiber. In Figure 12, the correlation coefficient $\left(R^{2}\right)$ is found to be 0.97 , suggesting that the two-parameter Weibull fit the experimental data fairly well, although some deviation from the best fit line occurred. 
Table 2. Weibull modulus $(\alpha)$, scale parameter $\left(\sigma_{0}\right)$, correlation coefficient $\left(R^{2}\right)$ of the Weibull distribution equation (obtained from Figure 12).

\begin{tabular}{ccc}
\hline Parameter & Symbol & Values \\
\hline Weibull modulus & $\alpha$ & 1.667 \\
Constant term & $c$ & -3.530 \\
Scale parameter & $\sigma_{0}=\exp ^{-\left(\frac{c}{\alpha}\right)}$ & 8.3 \\
Precision adjustment & $R^{2}$ & 0.97 \\
\hline
\end{tabular}

The calculated values of the Weibull modulus and the scale parameter were found to be 1.7and 8.3, respectively. Similar values for the Weibull modulus have been observed in other lignocellulosic fibers [48].

\section{Discussion}

The strength of composite materials is critically dependent on the strength distribution of the reinforcing fibers. Therefore, establishing the reliability for industrial applications requires extensive testing and a substantial amount of research. In fact, the variability in mechanical properties of natural fibers is one of the major concerns for final product application. Hence, a good understanding of the scattering behavior of tensile properties may shed light on their safe industrial utilization. Owing to their hydrophilic nature, bagasse fibers usually do not have good adhesion either in thermoplastics or thermoset matrices [49,50]. The application of alkali treatment improves the adhesion between the fiber and the matrix [24]. Cellulose, hemicellulose, and lignin are the three main components of bagasse fibers. During alkali treatment, hemicellulose, lignin, and other components such as pectin, fat, and wax were solubilized, whereas the cellulosic portion was not significantly affected by $\mathrm{NaOH}$ [51]. This resulted in increased surface roughness, providing for improved interfacial bonding [52]. Y Cao et al. [53] reported that bagasse fiber pretreated with $1 \% \mathrm{NaOH}$ showed improved tensile strength, flexural strength and impact strength. Similar observations of jute fiber have been reported by Ray et al. [54]. The present observations (Figures 6 and 7) indicate that the alkali treatment changes the surface morphology of bagasse fibers, making the surface of the fiber cleaner yet uneven, in line with the previous study $[51,54]$. In addition to their hydrophilic nature, the bagasse fibers used in the present study showed significant diameter variation both between and within fibers (Figures 8 and 9). Similar diameter variations have been observed in other natural fibers such as wool [55], bamboo fibers [44], sisal fiber [56], and jute fiber [57]. However, the fiber diameter distributions observed in the present study were higher than those reported by Reddy and Yang [58] and M. Siti Alwani et al. [59]. Generally, the origin, quality of plant, location, weather, age, and fiber extraction method employed control the properties of natural fibers [60]. As reported in Section 3.1, the bagasse fibers used in the present study were manually extracted from the dried fibrous residue. Therefore, both natural conditions and the extraction method employed may have resulted in such variation.

Strength tests of bagasse fiber clearly showed wide variations in the breaking strength (Figure 10). Such variations could be attributed to several factors including the fiber diameter, gauge length, and fiber fracture mechanism. Monterio et al. [61] reported that thicker lignocellulosic fibers break at a lower stress than that required for thinner fibers. The distribution of both weak and stronger fibrils is relatively high in thicker fibers. During tensile deformation, the weakest fibrils in the thicker fiber fracture at a lower stress than that required for the fibril (the weakest) in the thinner fiber. Once the weakest fibril is fractured, it nucleates a flaw in the fiber structure, which then propagates in a brittle manner until complete rupture. Thus, a fiber with a smaller diameter will be stronger compared to one with a larger diameter. In addition, fiber strength was found to be negatively correlated to fiber gauge length $[46,59,62-64]$. Furthermore, as the fiber gauge length increases, the distribution of flaws also increased the probability of the presence of a larger fatal flow, which leads to the localization of stress and thereby reduces fiber strength. Our results show that the synergistic effect of thick bagasse fiber, high gauge length, and fiber fracture 
mechanism establishes local conditions for fracture and causes not only low breaking strength but also considerable scatter. This clearly indicates that the tensile properties of bagasse fiber cannot be characterized completely using deterministic models. Therefore, the two-parameter Weibull distribution has been applied in the present study to explain the strength variation of fibers. Let us assume that the flaws in the bagasse fibers represent both the diameter variation and fiber fracture mechanism. Therefore, in the present study, the Weibull modulus, $\alpha$, can be defined as the flaw frequency distribution. The high value of $\alpha$ suggests evenly distributed flaws throughout the material, resulting in strength that is independent of the gauge length and low strength variability. In contrast, low values of $\mathrm{m}$ represent fewer and less evenly distributed flaws, resulting in considerable scatter in strength. Natural fibers usually have a Weibull modulus between 1 and 6 [44]. The value of $\alpha$ for the bagasse fibers studied was relatively low (1.7, Table 2), which would be connected with brittle materials and it indicated that flaws in the bagasse fibers are distributed heterogeneously. Consequently, the tensile properties of bagasse fiber should be assessed statistically, rather than a single average experimental value.

The Weibull analysis provides guidance related to the overall performance of bagasse fibers, rather than relying on the average fiber strength and standard deviation. Although the Weibull modulus is comparatively low, there is the possibility that material with a larger $\alpha$ could be selected for the use.

The effect of alkali treatment on the structure and properties of natural fibers was studied by various research groups by changing the concentration of $\mathrm{NaOH}$ (from $0.03-40 \mathrm{wt} \%$ ) and the time of treatment (from a few minutes to $48 \mathrm{~h}$ ) [64,65]. It is generally accepted that the alkali treatment affects the composition, structure, the degree of crystallinity, pore structure, cellulosic fibril $[64,66]$, microfibril angle [64,67], and crystal modification (the transformation from the cellulose I to the cellulose II form as the result of the treatment) [68]. Therefore, precise and accurate characterization of the effect of alkali treatment on bagasse fiber is of crucial importance. Concerning the crystallinity index, it has been reported that the crystallinity index increases [64], decreases [69] or goes through a maximum [70,71] as a function of $\mathrm{NaOH}$ concentration and time. For this purpose, further systematic research must be carried out by varying the $\mathrm{NaOH}$ concentration and time. Therefore, it would be more instructive to use X-ray diffraction (XRD) to identify the crystallinity changes and the change of the microfibril angle (MFA) by varying the $\mathrm{NaOH}$ concentration and time. Several authors have also reported that owing to the alkali treatment, the hemicellulose, lignin, and wax content of the natural fibers decrease and the cellulose content increases. Fourier transform infrared spectroscopy (FTIR) must be carried out to understand the change in the chemical composition of the alkali-treated bagasse fibers; therefore, further investigation is still required. Furthermore, for a better understanding of the fiber fracture mechanism, direct observation of the 3D fracture behavior using X-ray microtomography is preferred. This procedure has a clear advantage over the traditional simple observation (observation of fracture surface under SEM) because it provides unique possibilities for detecting fracture origin in a quantitative manner.

\section{Conclusions}

An investigation of the surface morphology, geometry variation, and tensile properties of bagasse fibers was presented for potential application as reinforcement in composites. The results showed that the alkali treatment changes the surface morphology of bagasse fibers making the fiber surface rough $\left(R_{a}\right.$ of treated fiber is about 1.6 times higher than that of untreated fiber). The observed lower rupture stress is not only due to the accumulation of defects but also between-fiber and within-fiber diameter variations. Furthermore, the two-parameter Weibull fit the experimental data fairly well ( $R^{2}$ is found to be 0.97$)$. The Weibull modulus $(\alpha)$ was found to be 1.2, indicating that the strength distribution is high (has a higher scatter). The obtained results can be used as feedback for optimizing the bagasse fiber extraction and further fiber preparation. 
Author Contributions: Conceptualization, M.S.B. and M.A.R.; Formal analysis, M.S.F. and M.M.H.; Investigation, M.S.F. and M.M.H.; Methodology, M.S.B.; Supervision, M.S.B.; Writing—original draft, M.S.B.; Writing-review and editing, M.A.R. All authors have read and agreed to the published version of the manuscript.

Funding: This research received no external funding.

Institutional Review Board Statement: Not applicable.

Informed Consent Statement: Not applicable.

Data Availability Statement: All data is included in the manuscript.

Acknowledgments: Mechanical and Production Engineering Department, Ahsanullah University of Science and Technology, Dhaka, Bangladesh.

Conflicts of Interest: The authors declare no conflict of interest.

\section{References}

1. Ku, H.; Wang, H.; Pattarahaiyakoop, N.; Trada, M. A review of tensile properties of natural fiber reinforced polymer composites. Compos. Part B 2011, 42, 856-873. [CrossRef]

2. Paukszta, D.; Borysiak, S. The influence of processing and the polymorphism of lignocellulosic fillers on the structure and properties of composite materials-A review. Materials 2013, 6, 2747-2767. [CrossRef]

3. Arbelaiz, A.; Pantero, G.; Frenandez, B.; Mondragon, I.; Ganan, P.; Kenny, J.M. Flax fiber surface modifications: Effects on fiber physico mechanical and flax/polypropylene interface properties. Polym. Compos. 2005, 26, 224-332. [CrossRef]

4. Wang, F.; Shao, J. Modified Weibull Distribution for Analyzing the Tensile Strength of Bamboo Fibers. Polymers 2014, 6, 3005-3018. [CrossRef]

5. Siddiquee, M.; Helali, M. Effects of fiber length and fiber ratio on the biodegradability of jute polymer composites. Int. J. Sci. Eng. Res. 2014, 2, 64-69.

6. Mirbagheri, J.; Tajvidi, M.; Hermanson, J.C.; Ghasemi, I. Tensile properties of wood flour/kenaf fiber polypropylene hybrid composites. J. Appl. Polym. Sci. 2007, 105, 3054-3059. [CrossRef]

7. Li, Y.; Hu, C.; Yu, Y. Interfacial studies of sisal fiber reinforced high density polyethylene (HDPE) composites. Compos. Part A Appl. Sci. Manuf. 2008, 39, 570-578. [CrossRef]

8. Islam, M.N.; Rahman, M.R.; Haque, M.M. Physico-mechanical properties of chemically treated coir reinforced polypropylene composites. Compos. Part A Appl. Sci. Manuf. 2010, 41, 192-198. [CrossRef]

9. Bledzki, A.K.; Mamun, A.A.; Karuk, O. Abaca fibre reinforced PP composites and comparison with jute and flax fibre PP composites. Polym. Lett. 2007, 11, 755-762. [CrossRef]

10. Redy, C.R.; Sardashti, A.P.; Simon, L.C. Preparation and characterization of polypropylene-Wheat straw-Clay composites. Compos. Sci. Technol. 2010, 70, 1674-1680. [CrossRef]

11. Rahman, M.S.; Khatun, S.; Rahman, M.K. Sugarcane and surgar industry in Bangladesh: An Overview. Sugar. Technol. 2016, 18, 627-635. [CrossRef]

12. Vilay, V.; Mariatti, M.; Taib, R.; Todo, M. Effect of fiber surface treatment and fiber loading on the properties of bagasse fiber-reinforced unsaturated polyester composites. Compos. Sci. Technol. 2008, 68, 631-638. [CrossRef]

13. Wirawan, R.; Sapuan, S.M.; Yunus, R.; Abdan, K. Properties of sugarcane bagasse/poly(vinyl chloride) composites after various treatments. J. Compos. Mater. 2011, 45, 1667-1674. [CrossRef]

14. Vazquez, A.; Dominguez, V.A.; Kenny, J.M. Bagasse fiber-polypropylene based composites. J. Thermoplast. Compos. Mater. 1999, 12, 477-497. [CrossRef]

15. Da Luz, S.M.; da Costa, S.M.; Goncalves, A.R.; Arco Junior, A.P.D.; da Costa, S.A. Polypropylene Composites Reinforced with Biodegraded Sugarcane Bagasse Fibers: Static and Dynamic Mechanical Properties. Mater. Res. 2016, 19, 75-83. [CrossRef]

16. Naguib, H.M.; Kandil, U.F.; Hashem, A.I.; Boghdadi, Y.M. Effect of fiber loading on the mechanical and physical properties of green bagasse-polyester composite. J. Radiat. Res. Appl. Sci. 2015, 8, 544-548. [CrossRef]

17. Candido, V.S.; da Silva, A.C.R.; Simonassi, N.T.; da Luz, F.S.; Monteiro, S.N. Toughness of polyester matrix composites reinforced with sugarcane bagasse fibers evaluated by Charpy impact tests. J. Mater. Res. Technol. 2017, 6, 334-338. [CrossRef]

18. Stael, G.C.; Tavares, M.I.B.; Md'Almeida, J.R.M. Impact behavior of sugarcane bagasse waste-EVA composites. Polym. Test. 2018, 20, 869-872. [CrossRef]

19. Pasquini, D.; Teixeira, E.M.; Curvelo, A.A.; Belgacem, M.N.; Dufresne, A. Surface esterification of cellulose fibers: Processing and characterization of low-density polyethylene/cellulose fibres composites. Compos. Sci. Technol. 2008, 68, 193-201. [CrossRef]

20. Huang, Z.; Wang, N.; Zhang, Y.; Hu, H.; Luo, Y. Effect of mechanical activation pretreatment on the properties of sugarcane bagasse/poly(vinyl chloride) composites. Compos. Part A Appl. Sci. Manuf. 2012, 43, 114-120. [CrossRef]

21. Ahmadi, F.; Zamiri, M.J.; Khorvash, M.; Ziaee, E.; Polikarpov, I. Pre-treatment of sugarcane bagasse with a combination of sodium hydroxide and lime for improving the ruminal degradability: Optimization of process parameters using response surface methodology. J. Appl. Anim. Res. 2015, 44, 287-296. [CrossRef] 
22. Arrakhiz, F.Z.; Malha, M.; Bouhfid, M.; Benmoussa, K.; Qaiss, A. Tensile, flexural and torsional properties of chemically treated alfa, coir, and bagasse reinforced polypropylene. Compos. B Eng. 2013, 47, 35-41. [CrossRef]

23. Mittal, V.; Sinha, S. Effect of chemical treatment on thermal properties of bagasse fiber-reinforced epoxy composite. Sci. Eng. Compos. Mater. 2017, 24, 237-243. [CrossRef]

24. Li, L.; Yu, J.; Cheng, L.Q.W. Mechanical properties of poly (butylene succinate) (PBS) biocomposites reinforced with surface modified jute fibre. Compos. Part A Appl. Sci. Manuf. 2009, 40, 669-674. [CrossRef]

25. Luz, S.M.; Gonçalves, A.R.; Del'arco, A.P. Mechanical behavior and microstructural analysis of sugarcane bagasse fibers reinforced polypropylene composites. Compos. Part A Appl. Sci. Manuf. 2007, 38, 1455-1461. [CrossRef]

26. Barbero, E.; Feernandez-Saez, J.; Navarro, C. Statistical analysis of the mechanical properties of composite materials. Compos. $B$ Eng. 2000, 31, 375-381. [CrossRef]

27. Biariotti Puglia, D.; Torre, L.; Kenny, J.M.; Arbelaiz, A.; Cantero, G.; Matieta, C.; LIano-ponte, R.; Mondragon, I. A systematic investigation on the influence of the chemical treatment of natural fibers on the properties of their polymer matrix composites. Polym. Compos. 2004, 25, 470-479.

28. Tiryakioğlu, M.; Hudak, D.; Ökten, G. On evaluating Weibull fits to mechanical testing data. Mater. Sci. Eng. A 2009, 527, 397-399. [CrossRef]

29. Weibull, B.W. A Statistical Distribution Function of Wide Applicability. J. Appl. Mech. 1951, 18, 293-297. [CrossRef]

30. Doremus, R.H. Fractue statistis: A comparison of the normal, Weibull, and Type I extrement vlaue distributions. J. Appl. Phys. 1983, 54, 193-198. [CrossRef]

31. Schneider, C.A.; Rasband, W.S.; Eliceiri, K.W. NIH Image to ImageJ: 25 years of image analysis. Nat. Methods 2012, 9, 671-675. [CrossRef]

32. Hu, W.; Ton-That, M.T.; Sarazin, F.P.; Denault, J. An improved method for single fiber tensile test of natural fibers. Polym. Eng. Sci. 2010, 50, 819-825. [CrossRef]

33. Chi, Z.; Chou, T.W.; Shen, G. Determination of single fibre strength distribution from fibre bundle testing. J. Mater. Sci. 1984, 19, 3319-3324. [CrossRef]

34. Avdelidis, N.P.; Delegou, E.T.; Almond, D.P.; Moropoulou, A. Surface roughenss evalualtion of marble by 3D laser profilometry and pulsed thermography. NDTE Int. 2004, 37, 571-575. [CrossRef]

35. Poon, C.Y.; Bhushan, B. Comparison of surface roughness measurements by stylus profiler, AFM and non-contact optical profiler. Wear 1995, 190, 76-88. [CrossRef]

36. Sato, H.; O-hori, M. Surface roughness measurement using scanning electron microscope with digital processing. ASME J. Eng. Ind. 1987, 109, 106-111. [CrossRef]

37. Shi, Q.; Roux, S.; Latourte, F.; Hild, F.; Loisnard, D.; Brynaert, N. Measuring topographies form conventional SEM acquisitions. Ultramicroscopy 2018, 191, 18-33. [CrossRef]

38. Chinga, G. Detailed paper surface characterization for gloss assessment. J. Pulp. Pap. Sci. 2004, 30, $222-227$.

39. Chinga, G. SurfCharJ. 2003. Available online: http:// www.gcsca.net (accessed on 8 December 2020).

40. Chinga, G.; Johnsen, P.O.; Dougherty, R.; Berli, E.L.; Walter, J. Quantification of the 3D microstructure of SC surfaces. J. Mircorsc. 2007, 227, 254-265. [CrossRef]

41. Webb, H.K.; Troung, V.K.; Hasan, J.; Fluke, C.; Crawford, R.J.; Ivanova, E.P. Roughness parameters for standard description of surface nanoarchitectue. Scanning 2012, 34, 257-263. [CrossRef]

42. Horvath, R.; Dregelyi-Kiss, A.; Matyasi, G. The examination of surface roughness parameters in the fine turning of hypereutectic aluminum alloys. UPB Sci. Bull. 2015, 77, 205-216.

43. Monteiro, S.N. Properties and structure of Attalea funifera piassava fibers for composite reinforcement-A critical discussion. J. Nat. Fibers 2008, 6, 191-203. [CrossRef]

44. Trujillo, E.; Moesen, M.; Osorio, L.; Van Vuure, A.W.; Ivens, J.; Verpoest, I. Bamboo fibers for reinforcement in composite materials: Strength Weibull analysis. Compos. Part A Appl. Sci. Manuf. 2014, 61, 115-125. [CrossRef]

45. Monteiro, S.N.; Margem, F.M.; de Obraga, F.; da Luz, F.S.; Simonassi, N.T. Weibull analysis of the tensile strength dependence with fiber diameter of giant bamboo. J. Mater. Res. Technol. 2017, 6, 317-322. [CrossRef]

46. De Andrade Silva, F.; Chawla, N.; de Toledo Filho, R.D. Tensile behavior of high performance natural (sisal) fibers. Compos. Sci. Technol. 2008, 68, 3438-3443. [CrossRef]

47. Zhang, Y.P.; Wang, X.G.; Pan, N.; Postle, R. Weibull analysis of the tensile behavior of fibers with geometrical irregularities. J. Mater. Sci. 2002, 37, 1401-1406. [CrossRef]

48. Xia, Z.P.; Yu, J.Y.; Cheng, L.D.; Liu, L.F.; Wang, W.M. Study on the breaking strength of jute fibers using modified Weibull distribution. Compos. Part A Appl. Sci. Manuf. 2009, 40, 54-59. [CrossRef]

49. Alvarez, V.A.; Ruscekaite, R.A.; Vazquez, A. Mechanical Properties and Water Absorption Behavior of Composites Made from Biodegradable Matrix and Alkaline-Treated Sisal Fibers. J. Compos. Mater. 2003, 37, 1575-1588. [CrossRef]

50. Xue, L.; Lope, G.T.; Panigrahi, S. Chemical Treatments of Natural Fiber for Use in Natural Fiber-Reinforced Composites: A Review. J. Polym. Environ. 2007, 15, 25-33.

51. Rezende, C.A.; de Lima, M.A.; Maziero, P.; de Azevedo, E.R.; Garcia, W.; Polikarpov, I. Chemical and morphological characterization of sugarcane bagasse submitted to a delignification process for enhanced enzymatic digestibility. Biotechnol. Biofuels 2011, 4, 1-18. [CrossRef] 
52. Pickering, K.L.; Efendy, M.G.A.; Le, T.M. A review of recent developments in natural fiber composites and their mechanical performance. Compos. Part A Appl. Sci. Manuf. 2016, 83, 98-112. [CrossRef]

53. Cao, Y.; Shibata, S.; Fukumoto, I. Mechanical properties of biodegradable composites reinforced with bagasse fiber before and after alkali treatments. Compos. Part A Appl. Sci. Manuf. 2006, 37, 423-429. [CrossRef]

54. Roy, D.; Sarkar, B.K. Characterization of alkali-treated jute fibers for physical and mechanical properties. J. Appl. Polym. Sci. 2001, 80, 1013-1020. [CrossRef]

55. Wang, X. Predicting the strength variation of wool from its diameter variation. Text. Res. J. 2000, 70, 191-194. [CrossRef]

56. Inacio, W.P.; Lopes, F.P.D.; Monterio, S.N. Diameter dependence of tensile strength by Weibull analysis: Part III sisal fiber. Rev. Mater. 2010, 15, 124-130. [CrossRef]

57. Bevitori, A.B.; Da Silva, I.L.A.; Lopes, F.P.D.; Monterio, S.N. Diameter dependence of tensile strength by Weibull analysis: Part II jute fiber. Rev. Mater. 2010, 15, 117-123. [CrossRef]

58. Reddy, N.; Yang, Y. Biofibers from agricultural byproducts for industrial applications. Trends Biotechnol. 2005, 23, 22-27. [CrossRef]

59. Siti Alwani, M.; Abdul Khalil, H.P.S.; Islam, M.N.; Sulaiman, O.; Zaidon, A.; Dungani, R. Microstructural Study, Tensile Properties, and Scanning Electron Microscopy Fractography Failure Analysis of Various Agricultural Residue Fibers. J. Nat. Fibers 2015, 12, 154-168. [CrossRef]

60. Mylsamy, K.; Rajendran, I. Investigation on physio-chemical and mechanical properties of raw and alkali-treated, Agave americana fiber. J. Reinf. Plast. Compos. 2010, 29, 2925-2935. [CrossRef]

61. Monterio, S.N.; Lopes, L.P.D.; Ferreira, A.S.; Nascimento, D.C.O. Natural fiber polymer matrix composites: Cheaper, tougher and environmentally friendly. JOM 2009, 61, 17-22. [CrossRef]

62. Defoirdt, N.; Biswas, S.; Vriese, L.; Tran, L.Q.N.; Acker, J.V.; Ahsan, Q.; Gorbatikh, L.; Vuure, A.V.; Verpoesta, I. Assessment of the tensile properties of coir, bamboo and jute fiber. Compos. Part A Appl. Sci. Manuf. 2010, 41, 588-595. [CrossRef]

63. Fidelis, M.E.A.; Pereira, T.V.C.; da Gomes, F.M.O.; de Slilva, F.A.; Filho, R.D.T. The effect of fiber morphology on the tensile strength of natural fibers. J. Mater. Res. Technol. 2013, 2, 149-157. [CrossRef]

64. Sawpan, M.A.; Pickering, K.L.; Fernyhough, A. Effect of various chemical treatments on the fibre structure and tensile properties of industrial hemp fibres. Compos. Part A Appl. Sci. Manuf. 2011, 42, 888-895. [CrossRef]

65. Guo, G.; Xiang, A.; Tian, H. Thermal and mechanical properties of eco-friendly poly (vinyl alcohol) films with surface treated bagasse fibers. J. Polym. Environ. 2018, 26, 3949-3956. [CrossRef]

66. Gassan, J.; Bledzki, A.K. Alkali treatment of jute fibers: Relationship between structure and mechanical properties. J. Appl. Polym. Sci. 1999, 71, 623-629. [CrossRef]

67. Courchene, C.E.; Peter, G.F.; Litvay, J. Cellulose microfibril angle as a determinant of paper strength and hygroexpansivity in Pinus taeda L. Wood Fiber Sci. 2006, 38, 112-120.

68. Gassan, J.; Mildner, I.; Bledzki, A.K. Influence of fiber structure modification on the mechanical properties of flax fiber-epoxy composites. Mech. Compos. Mater. 1999, 35, 435-440. [CrossRef]

69. Borysiak, S.; Garbarczyk, J. Applying the WAXS method to estimate the supermolecular structure of cellulose fibres after mercerization. Fibres Text. East. Eur. 2003, 11, 104-106.

70. Oushabi, A.; Sair, S.; Hassani, F.O.; Abboud, Y.; Tanane, O.; El Bouari, A. The effect of alkali treatment on mechanical, morphological and thermal properties of date palm fibers (DPFs): Study of the interface of DPF-Polyurethane composite. S. Afr. J. Chem. Eng. 2017, 23, 116-123. [CrossRef]

71. Das, M.; Chakraborty, D. Influence of alkali treatment on the fine structure and morphology of bamboo fibers. J. Appl. Polym. Sci. 2006, 102, 5050-5056. [CrossRef] 